\title{
Analyzing the Stimulus Control Acquisition in Simple Discrimination Tasks through Eye Movement
}

\author{
Análise da Aquisição de Controle de Estímulos em Tarefas \\ de Discriminação Simples por Meio do Movimento dos Olhos
}

\author{
Edson Massayuki Huziwara* ${ }^{*}$, Marcelo José Machado Silva ${ }^{b}$, \\ William Ferreira Perez ${ }^{c} \&$ Gerson Yukio Tomanari ${ }^{b}$ \\ ${ }^{a}$ Universidade Federal de Minas Gerais, Belo Horizonte, MG, Brasil, \\ ${ }^{b}$ Universidade de São Paulo, São Paulo, SP, Brasil \\ \& ' Paradigma-Centro de Ciências do Comportamento, São Paulo, SP, Brasil
}

\begin{abstract}
In order to investigate whether simultaneous or successive presentation of stimuli is related to the duration of eye fixation (i.e., the time spent gazing a specific stimulus), this study described the eye movements of young adults in simultaneous and successive simple discrimination tasks. Using 12 landscape scenes as visual stimuli, three participants were exposed to a simple discrimination training with simultaneously presented stimuli (Si Procedure) and then to a second simple discrimination training with successively presented stimuli (Su Procedure). Another three participants were exposed to the Procedure in the opposite order. In both cases, the learning criterion was that at least $90 \%$ of the responses should be correct in one block. Eye movements were recorded during the whole experiment. Participants achieved the learning criteria in both procedures. Beyond that, eye fixation time in the Su Procedure was higher than in the Si Procedure, regardless of the training sequence. Taken together with previous results in different experiments, our findings suggest that the duration of eye fixation plays a central role in the establishment of different stimulus control topographies. Keywords: Eye movements, eye fixation time, simultaneous discrimination, successive discrimination, young adults.
\end{abstract}

\begin{abstract}
Resumo
Com o objetivo de investigar se a apresentação simultânea ou sucessiva de estímulos estaria relacionada com a duração da fixação do olhar (i.e., o tempo gasto fixando um estímulo específico), este estudo descreveu os movimentos dos olhos de adultos em tarefas de discriminação simples simultâneas e sucessivas. Utilizando 12 cenas de paisagens como estímulos visuais, três participantes foram expostos a um treino de discriminação simples com estímulos apresentados simultaneamente (Procedimento Si) e, em seguida, a um segundo treino de discriminação simples com estímulos apresentados sucessivamente (Procedimento $\mathrm{Su}$ ). Outros três participantes foram expostos ao Procedimento em ordem inversa. Em ambos os casos, uma concentração mínima de $90 \%$ das respostas ao estímulo correto, em um mesmo bloco, definia a aquisição da discriminação. Os movimentos dos olhos foram registrados durante todo o experimento. Participantes atingiram os critérios de aquisição da discriminação em ambos os procedimentos. Além disso, o tempo de fixação do olhar no Procedimento Su foi maior do que no Procedimento $\mathrm{Si}$, independentemente da sequência de treino. Considerados em conjunto com resultados prévios em diferentes experimentos, nossos dados sugerem que a duração da fixação do olhar exerce um papel central no estabelecimento de diferentes topografias de controle de estímulos. Palavras-chave: Movimentos dos olhos, tempo de fixação dos olhos, discriminação simultânea, discriminação sucessiva, jovens adultos.
\end{abstract}

By analyzing simple, everyday events, it is possible to verify that some aspects of the environment influence the probability of occurrence of behaviors. A red traffic light, a road sign, or an officer's signal are examples of environmental stimuli that influence the probability that a driver stops a vehicle. In behavior-analytic terms, one

"Mailing address: Rua Córrego da Mata, 590, Apto. 901, Bloco 1, Horto, Belo Horizonte, MG, Brazil 31030-030. E-mail: huziwara.edson@gmail.com says that an antecedent environmental stimulus acquired control over the occurrence of a determined behavior (Skinner, 1953, 1974), and this behavioral process has been experimentally investigated for many years.

Among the experimental designs used in this discipline, procedures that taught simple discrimination with the simultaneous and successive presentation of stimuli can be highlighted. A simple simultaneous discrimination procedure with pigeons, for example, can be performed with the use of an experimental chamber with two response 
keys showing two visual stimuli (a triangle and a circle). The triangle is presented in the first key, and the circle is simultaneously presented in the second key. In this situation, pecking the triangle produces the reinforcer, whereas pecking the circle is followed by conventional consequences for errors. When the pigeon pecks the triangle in the majority of the trials, it is possible to say that a discriminated response was established.

A simple successive discrimination procedure can be performed with the use of an experimental chamber with only one response key and two visual stimuli. In this procedure, the stimuli are presented in the same key, but at alternating moments. In this second situation, pecking the key when the triangle is presented produces a reinforcer, whereas pecking the same key when the circle is presented is followed by conventional consequences for errors. Responding under discriminative control is verified when the subject emits a greater number of pecks at the moment when the triangle is presented, and fewer pecks at the moment when the circle is presented. In both procedures previously described, the triangle had the discriminative function of a positive stimulus $(\mathrm{S}+$, the stimulus related to the reinforcer), and the circle had the discriminative function of a negative stimulus ( $\mathrm{S}-$, the stimulus not related to the reinforcer).

Several experiments with human participants and nonhuman subjects have been carried out to compare the acquisition of the discriminated response in simultaneous and successive simple discrimination procedures (Bitterman, Tyler, \& Elam, 1955; Bitterman \& Wodinsky, 1953; Carter \& Eckerman, 1975; Grice, 1949; Lipsitt, 1961; Loess \& Duncan, 1952; MacCaslin, 1954; Mundy, Honey, \& Dwyer, 2007; North \& Jeeves, 1956; Weise \& Bitterman, 1951; Wodinsky, Varley, \& Bitterman, 1954). In most cases, especially with nonhuman subjects, the results suggest that simultaneous presentation of stimuli gives rise to a faster discrimination process when compared with successive presentation of stimuli (but exceptions are found in Bitterman et al., 1955; Bitterman \& Wodinsky, 1953; Weise \& Bitterman, 1951).

However, some authors have argued that a simple discrimination procedure with a successive presentation of stimuli increases the probability of establishing a discriminated response that is controlled by aspects of the $\mathrm{S}+$ and concurrently by aspects of the S- (Campos, Debert, Barros, \& McIlvane, 2011; Debert, 2003; Debert, Matos, \& McIlvane, 2007), which might not be the case in procedures with a simultaneous presentation of the stimuli.

Goulart, Mendonça, Barros, Galvão and Mcllvane (2005), for example, carried out an experiment with two monkeys (Cebus apella) which were trained in a simple discrimination task. The stimuli were abstract forms that were drawn in black on a gray background and presented on a touch screen. Touching the S+ was followed by small portions of banana and a 6-s intertrial interval (ITI). Touching the S- was followed only by the ITI. More specifically, the training procedure presented three trial types. The $\mathrm{S}+$ and the $\mathrm{S}-$ were simultaneously presented in Type
$\mathrm{I}$, and the correct response was to touch the $\mathrm{S}+$. Thus, the responses could be controlled only by the aspects of the $\mathrm{S}+$ and, in an opposite way, could be controlled only by the aspects of the S- (Carrigan \& Sidman, 1992; Goulart et al., 2005; Johnson \& Sidman, 1993; Perez \& Tomanari, 2008, 2013; Sidman, 1987, 1994), but it was not possible to ensure the relations established in those trial types. On trials in Type II, the $\mathrm{S}+$ and a white square were presented, and the correct response was also to touch $\mathrm{S}+$. Because of the absence of an S-, the participant had no alternative to reject it, and the response should have occurred necessarily under the control of the S+. Type III presented an S-and a white square. In this case, the correct response was to touch the white square. The subject could not emit a response under the control of an $\mathrm{S}+$ because it was not present. To obtain the reinforcer, the subject should have rejected the $\mathrm{S}-$ and have touched the white square. Thus, considering them together, Types II and III comprised situations of successive discrimination, and the participants presumably established relations controlled by selection and rejection.

To investigate whether simultaneous or successive stimulus presentation establishes different relations of control (selection or rejection) in simple discrimination procedures, an alternative could be recording eye movements. Schroeder (1970) analyzed, for example, eye movement behavior in college students. The objective was to evaluate a possible relationship between the frequency that a stimulus was observed and the choices emitted by the participants in tasks of simple simultaneous discrimination. Each trial began with the presentation of four stimuli that were presented in the corners of a screen. Two stimuli were designated as the $\mathrm{S}+$, and the other two were designated as the $\mathrm{S}-$. The participant emitted a choice response by clicking on a panel that had four buttons, where each button corresponded to each position of the stimulus presentation. Responses to the $\mathrm{S}+$ were followed by presentation of a green square in the center of the screen and a 3-s ITI. Responses to the $\mathrm{S}$ - were followed by the presentation of a red square and a 3-s ITI. The results demonstrated that the most frequently observed stimuli were also the ones that were the most often chosen. Based on results that are similar to those reported by Schroeder (e.g., Perez, Endemann, Pessôa, \& Tomanari, 2015; Pessôa, Huziwara, Perez, Endeman, \& Tomanari, 2009), it is possible that recording eye movements may provide a measure of the control exerted by each of the stimuli when they are presented in situations of simple simultaneous discrimination (Dinsmoor, 1985). According to Serna and Carlin (2001), discrimination acquisition depends on directing students' attention to the relevant aspects of the task. If this is true, eye movement issues in teaching situations could be the reason for restricted stimulus control problems (Dube et al., 2006; Dube et al., 2010), attention problems (Doran \& Holland, 1971) and many other aspects commonly related to failure in the learning process.

The present experiment was an exploratory study to investigate whether the duration of eye fixation (defined in terms of the time spent gazing a specific stimulus) is 
modulated by simultaneous or successive simple discrimination training procedures. Three participants were exposed to a simultaneous simple discrimination training (Si procedure) and then exposed to a successive simple discrimination training (Su procedure) with a different set of stimuli. Additionally, in order to control the order of training, three other participants were exposed to the $\mathrm{Su}$ procedure and then to the Si procedure.

\section{Method}

\section{Participants}

Participants were six undergraduate students, 20 to 24 years old, recruited through personal contacts. None of them had previous experience in behavioral analysis and declared that they did not have any noticeable visual deficits. Before initiating the experiment, the participants were informed of all of the procedures to which they would be exposed and signed an informed consent form.

\section{Setting and Apparatus}

The training procedure was performed in a $2.4 \mathrm{~m}$ room that was divided by a partition. On one side of the room, the participant remained sitting in front of a computer (Apple Macintosh Performa) with MTS software (Dube \& Hiris, 1999) that presented the trials and recorded the responses. The experimenter was on the other side of the room with computers that were used to record eye movements. An ISCAN model RK-426PC tracking system was used to monitor eye movement. The data produced by this system corresponded to a video of the participant's visual field $\left(20^{\circ} \times 20^{\circ}\right)$ in which an overlapping cursor indicated the location of sight fixation with $.3^{\circ}$ precision. The screen was approximately $50 \mathrm{~cm}$ away from the participant. The dimensions of the visual stimuli were approximately 4.5 $\mathrm{cm}$, which corresponded to a visual angle of approximately $5.7^{\circ}$

Participants' eye movements were recorded during the sessions. Video Frame Coder ${ }^{\circledR}$ software was used to transform the video into a continuous sequence of frames, and these frames were coded to indicate the direction of the participants' gaze at each moment of the session. According to the gaze position in each frame, the experimenter named this frame as $\mathrm{S}+$ (if the participants were gazing to the $\mathrm{S}+$ ), $\mathrm{S}$ - (if the participants were gazing to the $\mathrm{S}-$ ) or $\mathrm{N}$ (if the participants were gazing in any direction except $\mathrm{S}+$ or $\mathrm{S}-$ ). An independent researcher coded $10 \%$ of all the frames. Agreement between the experimenter's coding and the independent researcher's coding was calculated by dividing the number of agreements (frames coded with the same code) by the total number of evaluations (the sum of agreements and disagreements). In all cases, agreement between the observers was at least $80 \%$.

\section{Stimuli}

Stimuli were scanned paintings by the Japanese artist Utagawa Hiroshige (Hiroshige, 1986). Twelve paintings were chosen to form four sets with three stimuli each. Sets 1 and 2 (Figure 1, left columns) were used in the $\mathrm{Si}$ Procedure and Sets 3 and 4 (Figure 1, right columns) were used in the Su Procedure.

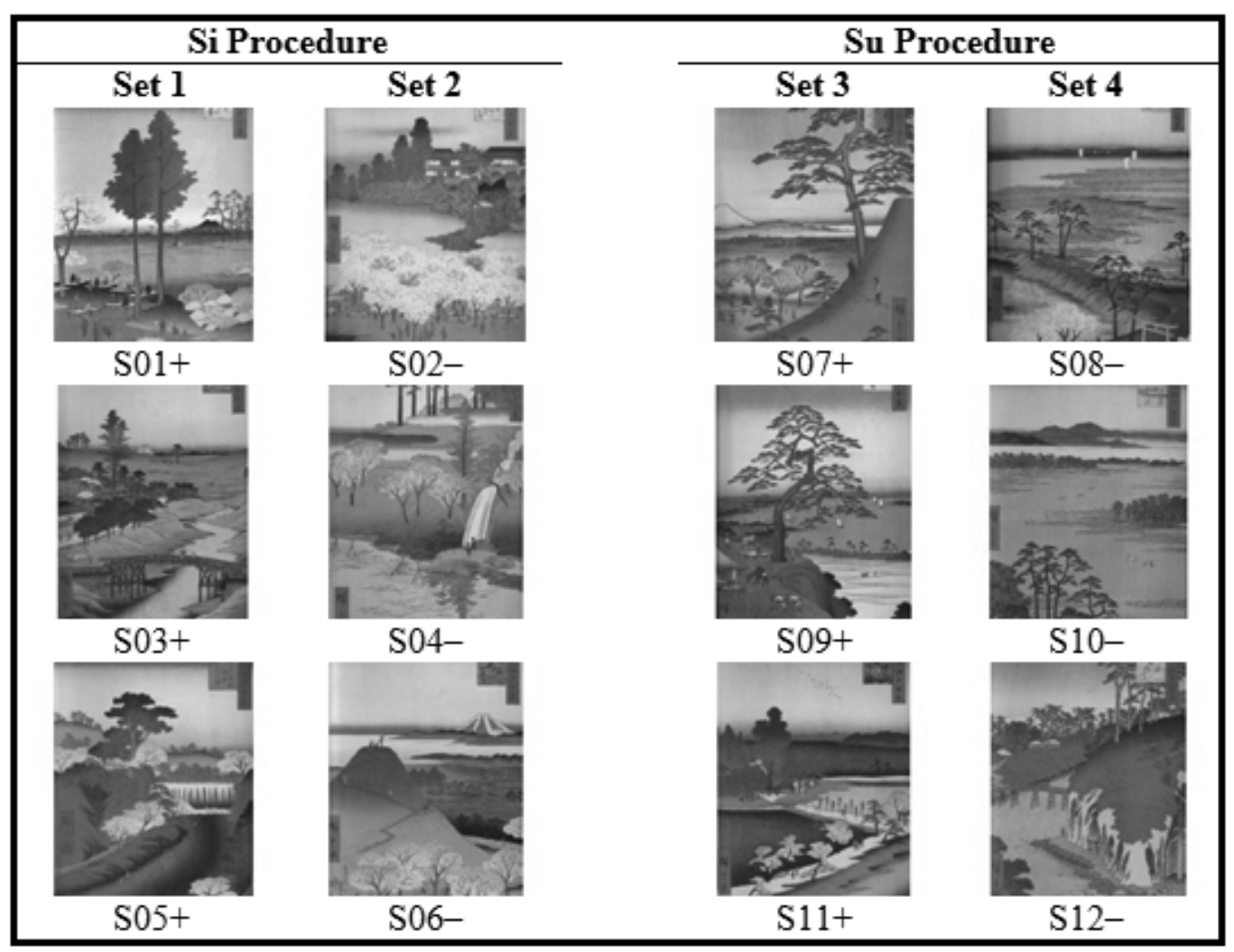

Figure 1. Sets of stimuli used in the Si Procedure and the Su Procedure. 


\section{Procedure}

Three participants were given the Si Procedure followed by the Su Procedure. Three other participants were given the reverse training order. In both training procedures, the responses were emitted using four buttons of the computer keyboard that corresponded to the position of stimulus presentation. The " $U$ " key corresponded to the upper left corner. The "O" key corresponded to the upper right corner. The "J" key corresponded to the lower left corner. The "L" key corresponded to the lower right corner.

In both training procedures, the differential consequences for correct and incorrect responses were the same. Correct responses added one point to the numerical counter on the upper middle part of the screen, a characteristic tone, the disappearance of both stimuli, and the start of a 1-s ITI.
Incorrect responses produced only the disappearance of both stimuli followed by the ITI (see Figure 2).

Si Procedure: Simple Simultaneous Discrimination. The trial began with the simultaneous presentation of two stimuli, one from Set 1 and other from Set 2. The number of presentations of each stimulus in each position and repetition of identical pairs were counterbalanced. In each trial, the correct response was defined as pressing the key that indicated the location where the Set 1 stimulus was presented. The incorrect response was defined as pressing the key that indicated the location where the Set 2 stimulus was presented. No time limit was imposed to complete the trial (i.e., the stimuli remained available until the participant emitted the choice response). The upper portion of Figure 2 shows an illustrative drawing of the contingencies that were in effect during the Si Procedure.

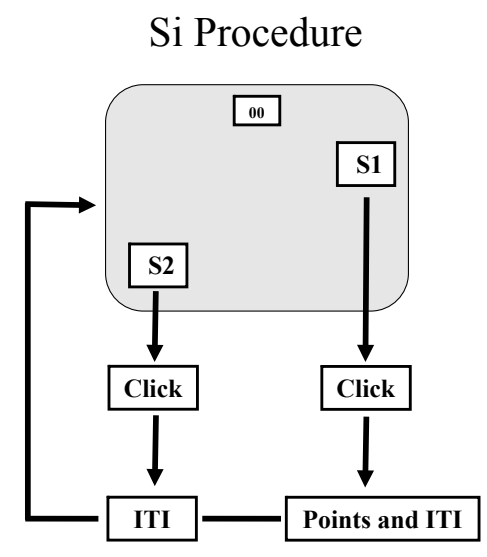

\section{$\mathrm{Su}$ Procedure}
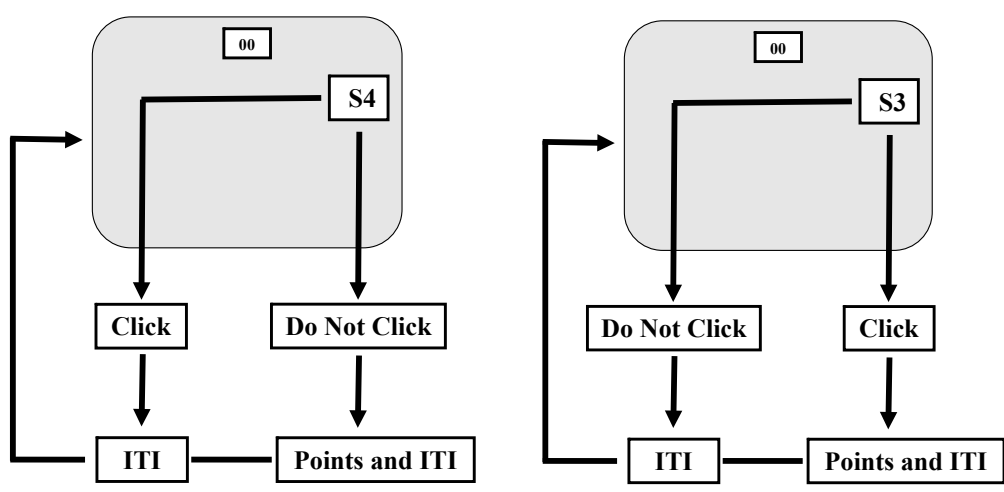

Figure 2. Schematic illustration of the contingencies in the Si and Su Procedures.

Trials were allocated in blocks of 36 , and the learning criterion was that at least $90 \%$ of the responses should be correct in a single block. If the criterion was not achieved after the repetition of four blocks, then the session was terminated and the participant was dismissed.

Su Procedure: Simple Successive Discrimination. A single stimulus was presented in one of the four positions for a maximum of $5 \mathrm{~s}$. In the trial in which one of the Set 3 stimuli was presented, a correct response was defined as pressing the key that corresponded to the location where the stimulus was presented within the 5-s time limit. An incorrect response was defined as not pressing the key that corresponded to the location where the stimulus was presented within the 5-s time limit. In the trials in which one of the Set 4 stimuli was presented, a correct response was defined as not pressing the key that corresponded to the location where the stimulus was presented within the 5-s time limit. An incorrect response was defined as press- 
ing the key that corresponded to the location where the stimulus was presented within the 5-s time limit.

Each block presented 24 trials that were equally divided among the stimuli of Sets 3 and 4. Therefore, there were 12 trials in which the correct response involved pressing the key that corresponded to the location of the presentation of the stimuli (i.e., trials with Set 3 stimuli), and there were 12 trials in which the correct responses

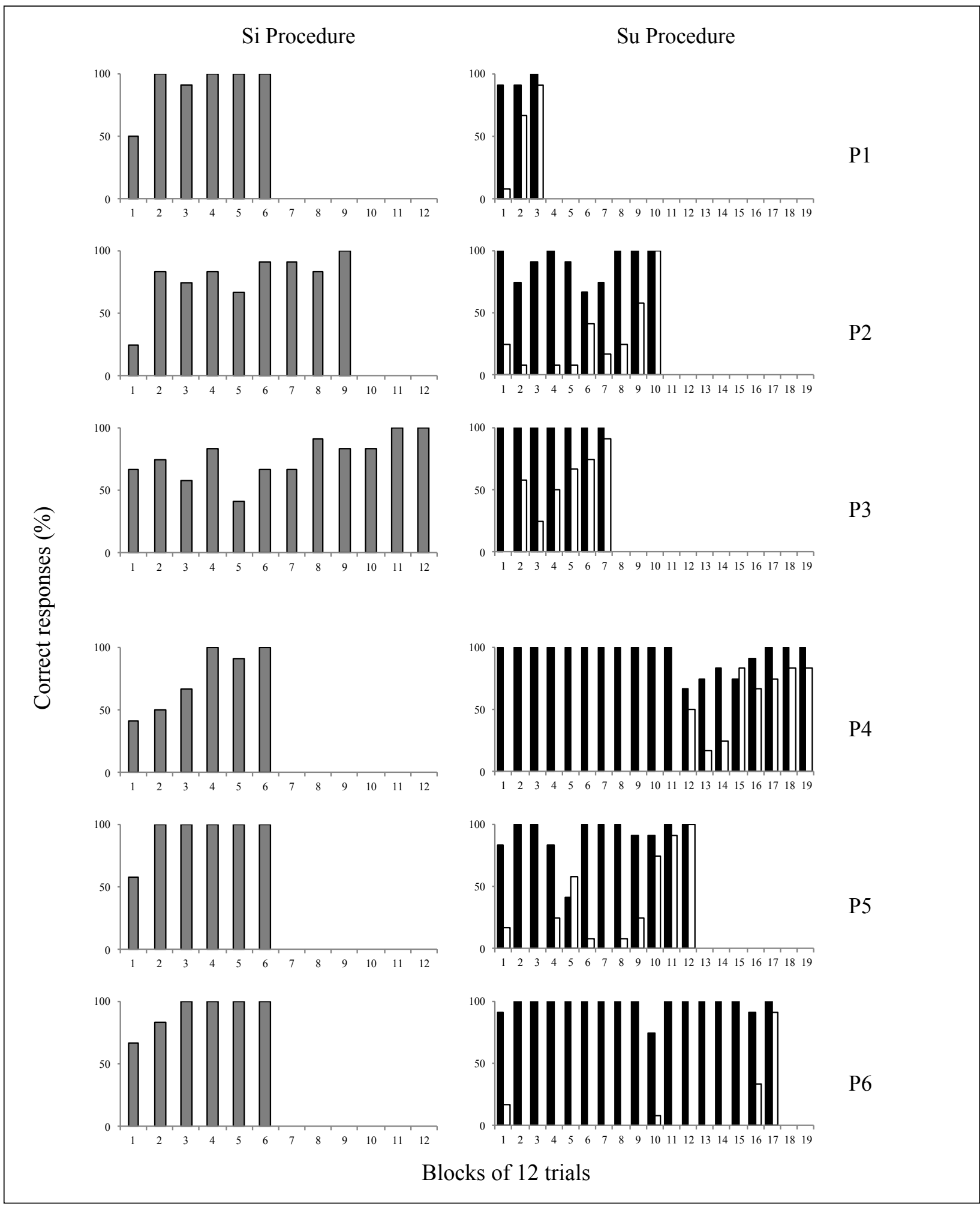

Figure 3. Percentage of correct responses in blocks of 12 trials in the Si and Su Procedures. In the left portion, gray bars represent the percentage of correct responses obtained by the participants during the Si Procedure. The right portion presents the results of the participants during the Su Procedure; the black bars represent the percentage of correct responses in trials that presented the Set 3 stimuli and the white bars represent the percentage of correct responses in trials with the Set 4 stimuli. 
consisted of waiting for the duration of the stimulus presentation without pressing the key (i.e., trials with Set 4 stimuli). The learning criterion was that at least $90 \%$ of the responses should be correct in the trials in a single block. If the criterion was not achieved after the repetition of four blocks, then the session was terminated and the participant was dismissed.

\section{Results}

As described in Procedure, the Si Procedure presented 36 trials per block and the Su Procedure presented 24 trials per block. Differing numbers trials were used to ensure that the time spent in each session was similar for participants in both procedures (Huziwara, 2010; Pessôa et al., 2009; Schroeder, 1970, 1997). However, to facilitate comparisons between the present results on the $\mathrm{Si}$ and $\mathrm{Su}$ procedures, data was analyzed in blocks of 12 in both cases.

In the left portion of Figure 3, gray bars represent the percentage of correct responses obtained by the participants during the Si Procedure. Despite the variability in the number of trials performed, all the participants achieved the learning criterion. Participants P1, P4, P5, and P6 achieved the learning criterion after 72 trials. Participants P2 and P3 needed 108 and 144 trials, respectively.

The right portion of Figure 3 presents the results of the participants during the Su Procedure. Each block of this training procedure had 12 trials in which one of the Set 3 stimuli was presented and another 12 trials in which one of the Set 4 stimuli was presented. The black bars represent the percentage of correct responses in the trials that presented the Set 3 stimuli, and the white bars represent the percentage of correct responses in the trials with the Set 4 stimuli.

Although they required different numbers of trials, all the participants initiated this training by clicking in almost all of the trials. This pattern of responses could be identified by a high percentage of correct responses in trials with Set 3 stimuli (scores nearly or equal to $100 \%$ ) and by a low percentage of correct responses in trials with Set 4 stimuli (scores nearly or equal to $0 \%$ ). The first 11 blocks for P4 are an example of this response pattern. Throughout the training procedure, an increase of correct responses in trials with the Set 4 stimuli was observed. This process occurred in a considerably gradual manner for participants P2, P3, P4, and P5, but in an abrupt manner for P1 and P6. Participants $\mathrm{P} 1, \mathrm{P} 2$, and $\mathrm{P} 3$ achieved the learning criterion after three, ten, and seven repetitions of the training block, respectively. Participants P4, P5, and P6 needed 18, 11, and 17 training blocks, respectively, to achieve the learning criterion. Due to an error of the experimenter, Participants P4 and P5 performed an additional block of trials after achieving the learning criterion.

Figure 4 shows the time spent observing each set of stimuli that were presented during the Si Procedure. In the left portion, gray bars represent the time spent observing the Set 1 stimuli $(\mathrm{S}+)$ and gray patterned bars represent the time spent observing the Set 2 stimuli (S-). The analysis of the results indicated that all the participants spent more time observing the Set 1 stimuli, regardless of the order of exposure to successive or simultaneous discrimination trials. The only exception occurred with P1, who spent more time observing the Set 2 stimuli in three of the six trial blocks. Also independent of the order of training exposure, all the participants reduced the time spent observing the stimuli over trials during the Si Procedure. Participant P3, for example, spent approximately $22 \mathrm{~s}$ observing the Set 1 stimuli and $15 \mathrm{~s}$ observing the Set 2 stimuli during the first 12 trials. However, in the last 12 trials, the same participant spent less than $5 \mathrm{~s}$ observing the Set 1 stimuli and $1.5 \mathrm{~s}$ observing the Set 2 stimuli.

Figure 4 also presents the time spent observing the stimulus sets that were presented during the Su Procedure. On the right portion, black bars represent the time spent observing the Set 3 stimuli and white bars represent the time spent observing the Set 4 stimuli. For all the participants, data analysis indicated that the time spent observing the stimuli systematically varied during the training blocks. In some cases, the increase in the duration of eye fixation coincided with the increase in the number of correct responses, especially for the Set 4 stimuli. Blocks from 12 to 19 for P4 and blocks from 8 to 12 for P5 are examples of this process. Finally, our findings demonstrate that the time spent observing the Set 4 stimuli increased throughout the blocks. Five of the six participants spent more than $40 \mathrm{~s}$ observing those stimuli in the last block of 12 trials, whereas the observation time varied between $1.5 \mathrm{~s}$ and $20 \mathrm{~s}$ during the first 12 trials.

Table 1 presents the average duration of eye fixation during the Si and Su Procedures. Results indicated that the stimuli with the function of the S+ were observed for an average of .65 s in the Si Procedure (Set 1) and .95 s in the Su Procedure (Set 3). The average time observing the stimuli with the function of the $\mathrm{S}-$ was $.49 \mathrm{~s}$ in the $\mathrm{Si}$ Procedure (Set 2) and $1.94 \mathrm{~s}$ in the Su Procedure (Set 4).

\section{Discussion}

The present experiment evaluated whether the form of stimulus presentation (i.e., in simultaneous or successive ways) in simple discrimination trainings modulates the time spent observing stimuli. Regardless of the order of training, a reduction of the time of stimulus observation was found for all of the participants in the Si Procedure. This same effect has been found in other experiments that used simple simultaneous discrimination training (Pessôa et al., 2009; Schroeder, 1970), denominated by Schroeder as an effect of practice on sight behavior. However, in the $\mathrm{Su}$ Procedure, the participants did not present the effect of practice. Indeed, the time spent observing the stimuli varied non-systematically, but it increased along the repetition of blocks, principally with regard to the time of stimulus observation with the function of S-. 
Time spent observing stimuli is modulated by the stimulus exposure time in each training session. In simultaneous training procedures, presentation of the stimuli is terminated when a choice response is emitted. However, in successive training procedures, there are trials in which the participant should wait for the presentation of the stimulus to be terminated. This fact certainly justifies the increase in the time spent observing the Set 4 stimuli in the Su Procedure compared with the time spent observing the Set 2 stimuli in the Si Procedure (see Figure 4). The

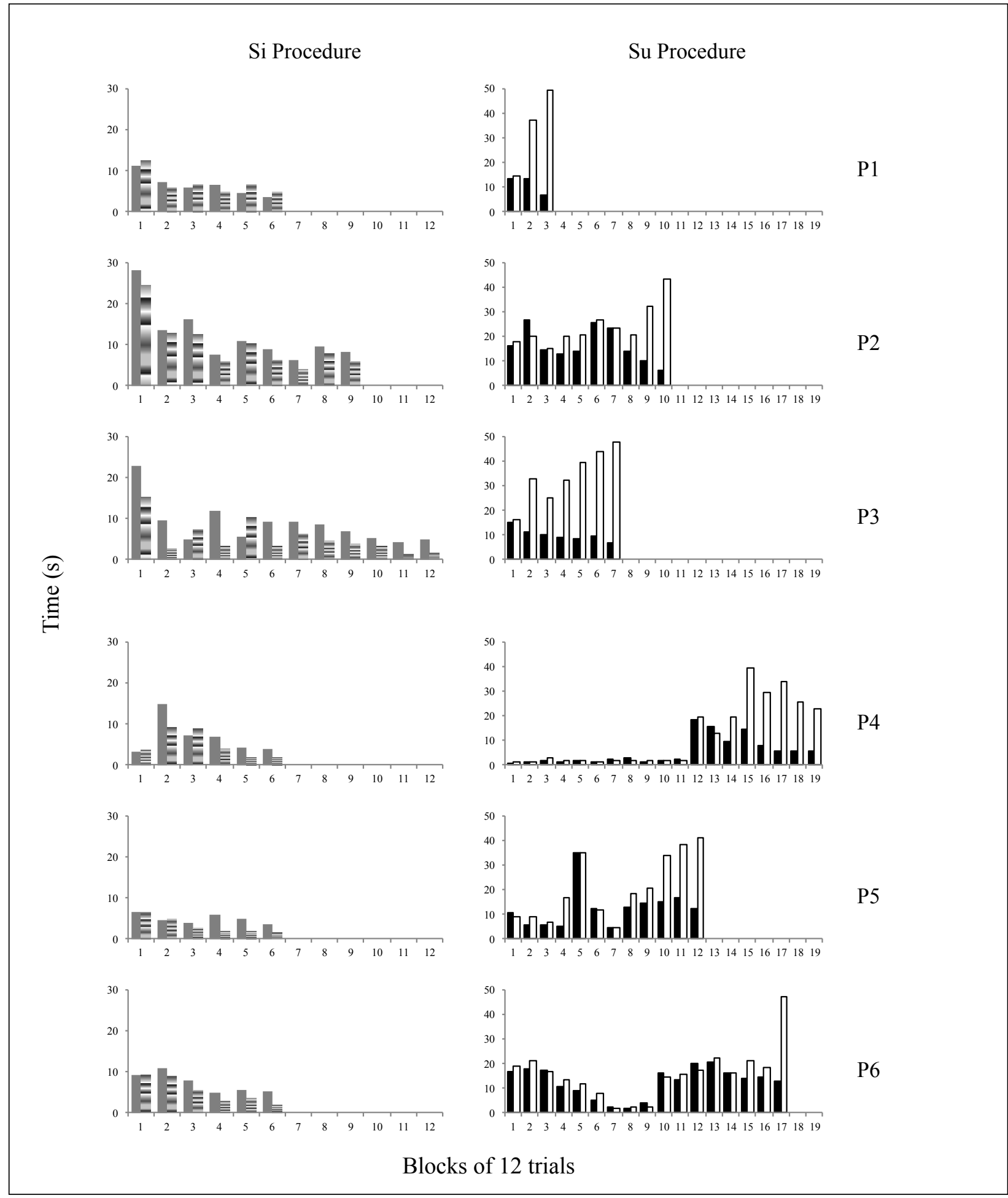

Figure 4. Time spent observing the set of stimuli in blocks of 12 trials in the Si and Su Procedures. The left portion presents results from the Si Procedure; gray bars represent the time spent observing the Set 1 stimuli ( $\mathrm{S}+$ ), and gray patterned bars represent the time spent observing the Set 2 stimuli (S-). The Su Procedure results are displayed on the right portion; black bars represent the time spent observing the Set 3 stimuli and white bars represent the time spent observing the Set 4 stimuli. 
Psychology/Psicologia Reflexão e Crítica, 28(3), 603-612.

Table 1

Average Time Spent Observing the Stimuli in the Si and Su Procedures

\begin{tabular}{ccccc}
\hline & \multicolumn{2}{c}{ Si Procedure } & \multicolumn{2}{c}{ Su Procedure } \\
\cline { 2 - 5 } & Set 1 (S+) & Set 2 (S-) & Set 3 (S+) & Set 4 (S-) \\
\hline P1 & .55 & .57 & .95 & 2.81 \\
P2 & 1.02 & .83 & 1.38 & 2.01 \\
P3 & .71 & .43 & .84 & 2.83 \\
P4 & .56 & .41 & .45 & .99 \\
P5 & .41 & .27 & 1.05 & 1.70 \\
P6 & .61 & .44 & 1.05 & 1.32 \\
& .64 & .49 & & \\
Mean & & & .95 & 1.94 \\
\hline
\end{tabular}

characteristics of each training type (i.e., simultaneous or successive) are implicated in how the time of exposure altered with the stimuli and consequently appear to modulate the time spent observing each of them.

However, if the characteristics of successive training procedures necessarily increase the time of exposure to the stimuli with the function of S-, the same possibility appears not to be true for the time of exposure to the stimuli with the function of $\mathrm{S}+$. In both training procedures, the termination of $\mathrm{S}+$ presentation depends on the choice response of the participant. Nonetheless, our findings suggest that the time of stimulus observation of S+ was greater in the Su Procedure. Therefore, successive training procedures appear to favor an increase in the time spent observing the stimuli, even in situations in which this observation time occurred independently of any other variable of the procedure.

A similar experiment using successive presentation of stimuli was carried out by Pessôa and Tomanari (2012). In that case, however, participant responses did not finish the trial. In other words, the time of presentation was the same in all trials, regardless of the stimuli presented (i.e., an $\mathrm{S}+$ or an $\mathrm{S}-$ ). In contrast to our findings, Pessôa and Tomanari described that there was little difference between the times spent observing stimuli with a positive or a negative function. What appears to be incompatibility of results between experiments could be better investigated in future experiments looking at the time that a stimulus is presented in discrimination tasks.

Differences in the time spent observing the stimuli between the Si and Su Procedures are also evident in the analysis of the results presented in Table 1. Only participants $\mathrm{P} 3$ and $\mathrm{P} 4$ presented an average of less than $.90 \mathrm{~s}$ in the Su Procedure. However, only P2 presented an average greater than $.90 \mathrm{~s}$ in the Si Procedure. Differences in the time spent observing the stimuli can be related to differences in learning task performance, as demonstrated by
Dube et al. (2006). The participants who obtained high percentages of correct responses in conditional discrimination tasks also increased the time spent observing the stimuli compared with participants who presented lower percentages of correct responses. Dube et al. also reported effects of continuous exposure to the training procedure. The participants who presented lower percentages of correct responses were given additional training sessions. The improvement in performance in these participants was accompanied by an increase in the time spent observing each of the presented stimuli.

Thus, considering that effective observation behavior can be a prerequisite for learning stimulus discriminative functions (Dinsmoor, 1985; Schroeder, 1997), the differences in the time spent observing the stimuli during simultaneous and successive training procedures may reflect differences in the establishment of stimulus control, as previously suggested (Campos et al., 2011; Debert, 2003; Debert et al., 2007). Although the present results are limited due to the number of participants and the absence of statistical analysis, recording eye movement behavior is suggested as a useful tool for investigating differences in the stimulus control relations that are established during various discriminative training procedures. Yet, in addition to eye-fixation measures, future studies would also benefit from using other tests to assess stimulus control, such as select/reject control probes (e.g., Goulart et al., 2005; for review, see Perez \& Tomanari, 2013; see also Carrigan \& Sidman, 1992). Thus, the measures of eye movement behavior could be contrasted with measures obtained in stimulus control probes, evaluating if differences in eye-fixations are, in some way, related to the establishment of select or reject control during the training. A similar suggestion was made by Perez et al. (2015). In their study, participants were exposed to a simultaneous discrimination task with compound stimuli and their eye fixations were recorded. 
After training, the components of the compound stimuli were separated and presented across different tests to assess stimulus control by each stimulus component. In general, participants tended to choose the S+ component on which their eyes had most fixated during training. The second-most fixated component, however, was from the $\mathrm{S}-$ and not from the $\mathrm{S}+$ component, which might indicate the occurrence of reject control. The authors suggest that eye-fixation analysis can be better interpreted when allied with further tests to assess stimulus control and also to encourage future studies using additional probes for assessing select and reject control.

\section{References}

Bitterman, M. E., Tyler, D. W., \& Elam, C. B. (1955). Simultaneous and successive discrimination under identical stimulating conditions. American Journal of Psychology, 68, 237-248. doi: $10.2307 / 1418894$

Bitterman, M. E., \& Wodinsky, J. (1953). Simultaneous and successive discrimination. Psychological Review, 60, 371-376. doi: $10.1037 / \mathrm{h} 0060508$

Campos, H. C., Debert, P., Barros, R. S., \& McIlvane, W. J. (2011). Relational discrimination by pigeons in a go/no-go procedure with compound stimuli: A methodological note. Journal of the Experimental Analysis of Behavior, 96, 417426. doi:10.1901/jeab.2011.96-413

Carrigan, P. F., \& Sidman, M. (1992). Conditional discrimination and equivalence relations: A theoretical analysis of control by negative stimuli. Journal of the Experimental Analysis of Behavior, 58, 183-204. doi:10.1901/jeab.1992.58-183

Carter, D. E., \& Eckerman, D. A. (1975). Symbolic matching by pigeons: Rate of learning complex discriminations predicted from simple discriminations. Science, 187, 662-664. doi: $10.1126 /$ science. 1114318

Debert, P. (2003). Relações condicionais com estímulos compostos (Tese de doutorado, Universidade de São Paulo, SP, Brasil).

Debert, P., Matos, M. A., \& McIlvane, W. J. (2007). Conditional relations with compound abstract stimuli using a go/no-go procedure. Journal of the Experimental Analysis of Behavior, 87, 89-96. doi:10.1901/jeab.2007.46-05

Dinsmoor, J. A. (1985). The role of observing and attention in establishing stimulus control. Journal of the Experimental Analysis of Behavior, 43, 365-381. doi:10.1901/ jeab.1985.43-365

Doran, J., \& Holland, J. G. (1971). Eye movements as a function of response contingencies measured by blackout technique. Journal of Applied Behavior Analysis, 4, 11-17. doi:10.1901/ jaba.1971.4-11

Dube, W. V., Balsamo, L. M., Fowler, T. R., Dickson, C. A., Lombard, K. M., \& Tomanari, G. Y. (2006). Observing behavior topography in delayed matching to multiple samples. The Psychological Record, 56, 233-244.

Dube, W. V., Dickson, C. A., Balsamo, L. M., Odonnell, K. L., Tomanari, G. Y., Farren, K. M., ...Mcllvane, W. J. (2010). Observing behavior and atypically restricted stimulus control. Journal of the Experimental Analysis of Behavior, 94, 297313. doi:10.1901/jeab.2010.94-297

Dube, W. V., \& Hiris, E. J. (1999). MTS software documentation. Waltham, MA: E. K. Shriver Center.
Goulart, P. R. K., Mendonça, M. B., Barros, R. S., Galvão, O. F., \& McIlvane, W. J. (2005). A note on select- and rejectcontrolling relations in the simple discrimination of capuchin monkeys (Cebus apella). Behavioural Processes, 69, 295-302. doi:10.1016/j.beproc.2004.12.005

Grice, G. R. (1949). Visual discrimination learning with simultaneous and successive presentation of stimuli. Journal of Comparative and Physiological Psychology, 42, 365-373. doi:10.1037/h0054773

Hiroshige, U. A. (1986). One hundred famous views of Edo [Paintings]. New York: George Braziller. Retrieved from http:// www.brooklynmuseum.org/opencollection/research/edo/

Huziwara, E. M. (2010). Controles por seleção e rejeição em discriminações condicionais em humanos e pombos (Tese de doutorado, Universidade de São Paulo, SP, Brasil).

Johnson, C., \& Sidman, M. (1993). Conditional discrimination and equivalence relations: Control by negative stimuli. Journal of the Experimental Analysis of Behavior, 59, 333-347. doi:10.1901/jeab.1993.59-333

Lipsitt, L. P. (1961). Simultaneous and successive discrimination learning in children. Child Development, 32, 337-347.

Loess, H. B., \& Duncan, C. P. (1952). Human discrimination learning with simultaneous and successive presentation of stimuli. Journal of Experimental Psychology, 44, 215-221. doi:10.1037/h0061719

MacCaslin, E. F. (1954). Successive and simultaneous discrimination as a function of stimulus similarity. American Journal of Psychology, 67, 308-314.

Mundy, M. E., Honey, R. C., \& Dwyer, D. M. (2007). Simultaneous presentation of similar stimuli produces perceptual learning in human picture processing. Journal of Experimental Psychology: Animal Behavior Processes, 33, 124-138. doi:10.1037/0097-7403.33.2.124

North, A. J., \& Jeeves, M. (1956). Interrelationships of successive and simultaneous discrimination. Journal of Experimental Psychology, 51, 54-58. doi:10.1037/h0045207

Perez, W. F., Endemann, P., Pessôa, C. V., \& Tomanari, G. Y. (2015). Assessing stimulus control in a discrimination task with compound stimuli: Evaluating testing procedures and tracking eye fixations. The Psychological Record, 65(1), 8388. doi:10.1007/s40732-014-0092-1.

Perez, W. F., \& Tomanari, G. Y. (2008). Controles por seleção e rejeição em treinos de discriminação condicional e testes de equivalência. Revista Brasileira de Análise do Comportamento, 4, 175-190.

Perez, W. F., \& Tomanari, G. Y. (2013). Inferindo a ocorrência dos controles por seleção e rejeição em tarefas de emparelhamento com o modelo: Uma revisão metodológica. Acta Comportamentalia, 21, 211-225.

Pessôa, C. V. B. B., Huziwara, E., Perez, W., Endemann, P., \& Tomanari, G. Y. (2009). Eye fixation to figures in a fourchoice situation with luminance balanced areas: Evaluating practice effects. Journal of Eye Movement Research, 2, 1-6.

Pessôa, C. V. B. B., \& Tomanari, G. Y. (2012). Medidas de controle de estímulos: Fixação do olhar como respostas de observação naturais. Revista Brasileira de Terapia Comportamental e Cognitiva, 14, 34-50.

Schroeder, S. R. (1970). Selective eye movements to simultaneously presented stimuli during discrimination. Perception \& Psychophysics, 7, 121-124. doi:10.3758/BF03210147

Schroeder, S. R. (1997). Selective eye fixations during transfer of discriminative stimulus control. In D. M. Baer \& E. M. Pinkston (Eds.), Environment and behavior (pp. 97-110). Boulder, CO: Westview. 
Serna, R., \& Carlin, M. T. (2001). Guiding visual attention in individuals with mental retardation. International Review of Research in Mental Retardation, 24, 321-357. doi:10.1016/ S0074-7750(01)80013-6

Sidman, M. (1987). Two choices are not enough. Behavior Analysis, 22, 11-18.

Sidman, M. (1994). Equivalence relations and behavior: A research story. Boston, MA: Authors Cooperative.

Skinner, B. F. (1953). Science and human behavior. New York: Macmillan.

Skinner, B. F. (1974). About behaviorism. New York: Knopf.

Weise, P., \& Bitterman, M. E. (1951). Response selection in discriminative learning. Psychological Review, 58, 185-195. doi: $10.1037 / \mathrm{h} 0062799$

Wodinsky, J., Varley, M. A., \& Bitterman, M. E. (1954). Situational determinants of the relative difficulty of simultaneous and successive discrimination. Journal of Comparative and Physiological Psychology, 47, 337-340. doi:10.1037/ h0062203 